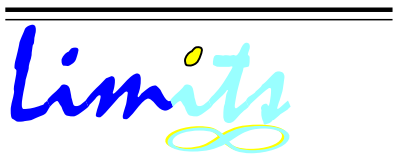

J. Math. and Its Appl.

ISSN : 1829-605X

Vol. 2, No. 1, May. 2005, 27-36

\title{
Pemodelan Fraktal: Study Kasus pada Nilai Tukar Dolar Amerika terhadap Rupiah
}

\author{
I Gst Ngr Rai Usadha, Erika Eka Santi \\ Jurusan Matematika \\ Institut Teknologi Sepuluh Nopember, Surabaya \\ ngurah@matematika.its.ac.id
}

\begin{abstract}
Abstrak
Dalam paper ini diaplikasikan teori praktal pada suatu data runtun waktu nilai tukar Dollar Amerika terhadap Rupiah. Dengan metode R/S dapat diperoleh parameter Hurst yang merupakan indeks keserupaan diri yang merupakan salah satu ciri fraktal. Dari model umum distribusi fraktal yang diperoleh, data return menunjukkan berdistribusi NonGauss.
\end{abstract}

Kata kunci: sifat keserupaan diri, parameter Hurst, metode $R / S$

\section{Pendahuluan}

Banyak fenomena ekonomi dan keuangan dimodelkan dengan asumsi distribusi yang berbentuk Gaussian. Seperti penelitian yang dilakukan Louis Bachelier, matematikawan Perancis, yang mengajukan model matematika untuk proses penyusunan data ekonomi keuangan dengan menggunakan metoda stokastik dari keuntungan (return). Model Bachelier tersebut menggunakan teori Gerak Brown dan memperlihatkan distribusi keuntungan yang berbentuk Gaussian. Dari penelitian Bachelier tersebut kemudian dijadikan dasar pengambilan asumsi pemodelan data ekonomi keuangan berdistribusi Gaussian. Namun penelitianpenelitian dewasa ini memperlihatkan penyimpangan terhadap model tersebut, 
sehingga data riil dari data ekonomi keuangan tidak selalu akurat jika dimodelkan dengan distribusi Normal,[5]. Maka dari itu, diperlukan pengembangan modelmodel ekonomi untuk mendapatkan model yang lebih realistis.

Benoit Mandelbrot, seorang ahli geometri fraktal, melakukan penelitian terhadap harga katun yang diperjualbelikan dan menemukan fakta menarik yaitu distribusi keuntungan untuk skala waktu yang berbeda memperlihatkan kemiripan atau bentuk yang universal. Dengan kata lain bahwa distribusi keuntungan tersebut memperlihatkan sifat keserupaan diri (self-similarity). Sejak saat itu banyak diyakini bahwa data return akan memiliki sifat fraktal yang dapat memperlihatkan pola keserupaan diri (self-similarity),[2].

Bertitik tolak dari hal tersebut, dalam paper ini dianalisa nilai tukar mata uang Dollar Amerika terhadap Rupiah (USD/IRD) menggunakan teori fraktal, yang lebih jauh dapat digunakan untuk mencari model distribusi data yang lebih realistis. Data yang diolah adalah nilai tukar harian mata uang Dollar Amerika terhadap Rupiah(USD/IDR) untuk periode waktu 1 Januari 1994 sampai dengan 20 Maret 2005 dengan sumber data adalah Oanda Corporation, (www.oanda.com)[6].

\section{Teori Dasar}

Pada bagian ini dibicarakan beberapa pengertian dasar yang akan dipakai sebagai dalam pembicaraan selanjutnya.

\subsection{Proses Keserupaan Diri}

Proses kesebangunan diri (self-similarity) adalah keidentikan (invariant) dalam distribusi pada skala waktu. Beberapa aspek dari sifat keserupaan diri tampak dalam geofisika, hidrologi, ekonomi, komunikasi.

Definisi 2.1 [2] Proses $\{X(t), t \in T\}, T=\{t, t \geq 0\}$ adalah proses keserupaan diri dengan indeks $H>0$ (dinotasikan dengan $H-$ ss) bila untuk semua nilai a $>0$ distribusi dari $\{X(a t), t \in T\}$ identik dengan distribusi dari $\left\{a^{H} X(t), t \in T\right\}$, yaitu untuk setiap $d \geq 1, t_{1}, t_{2}, \cdots, t_{d} \in T$ dan untuk setiap $a>0$,

$$
\left(X\left(a t_{1}\right), X\left(a t_{2}\right), \cdots, X\left(a t_{d}\right) i . d\left(a^{H} X\left(t_{1}\right), a^{H} X\left(t_{2}\right), \cdots, a^{H} X\left(t_{d}\right)\right)\right.
$$

dapat ditulis

$$
(X(a t), t \in T\} \text { i.d }\left\{a^{H} X(t), t \in T\right\}
$$




\subsection{Proses H-sssi, Proses Levy Motion dan Parameter Hurst (Hurst Exponent)}

Jika proses pembangkitan yang mendasari suatu data runtun waktu didasarkan pada nilai tengah dan varians konstan, maka runtun waktu stationer. Data runtun waktu adalah stationer jika sifat statistiknya bebas dari periode waktu selama pengamatan.

Definisi 2.2 [2] Proses $X(t)$ adalah $H$ - sssi (stabil-simetri-self similar) bila $X(t)$ self similar dengan index $H$ dan mempuyai increman yang stationer. Proses $X(t), t \in T$ dikatakan mempunyai increman yang stationer bila, untuk semua $h \in T$,

$$
X(t+h)-X(t) i . d X(t)-X(0)
$$

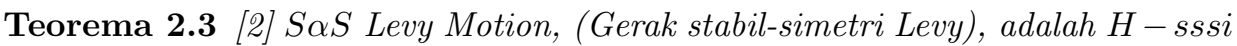
dengan indeks $H=-1 / \alpha, \alpha<-2$. Proses $\{X(t), t \geq 0\}$ dikatakan $\alpha-$ Levy Motion bila

1. $X(0)=0$;

2. $X$ memiliki increman yang independen yaitu untuk semua $a>0$ dan $t, s \in T$ maka

$$
X(a t)-X(a s) i . d a^{-1 / \alpha}(X(t)-X(s))
$$

Ukuran kekasaran (smothness) dari grafik data runtun waktu tergantung pada pendekatan perilaku dari proses rescaled range.

Definisi 2.4 [5] Parameter Hurst, H, didefinisikan sebagai

$$
H=\frac{\log (R / S)}{\log (T)}
$$

dimana $T$ adalah durasi dari contoh data, dan $R / S$ adalah nilai yang bersesuaian dari rescaled range. $H$ bernilai diantara satu dan nol $(0<H<1)$.

Parameter Hurst, $H$, mempunyai hubungan dengan dimensi fraktal $D$, yaitu $H=E+1-D$, dimana $E$ adalah dimensi Euclid ( $E=0$ untuk titik, $E=1$ untuk garis, $E=2$ untuk permukaan). Untuk sinyal satu dimensi $H=2-D$.

\subsection{Dimensi Fraktal}

Suatu himpunan $X$ dikatakan memiliki sifat keserupaan diri jika $X$ dapat dibagi menjadi $k$ subset (banyaknya pecahan data) yang sebangun yang masing-masing dapat digandakan dengan faktor konstan $M$ (banyaknya penggandaan) untuk menghasilkan himpunan semula. 
Definisi 2.5 [4] Dimensi fraktal $D$ dari $X$ didefinisikan sebagai

$$
D=\frac{\ln (k)}{\ln (M)}
$$

Dimensi fraktal $D=1.5$ memberi arti bahwa perilaku data runtun waktu sama dengan jalan acak yang berarti proses independen. Dimensi fraktal $1.5<H<2$, menunjukkan perilaku yang kuat (persistent behavior) yang dicirikan dengan efek memori panjang (long memory effect). (contoh dari 'persistent behavior' adalah autokorelasi positif). Bila dimensi fraktal $1<H<1.5$, maka menunjukkan 'antipersistent behavior' (mempunyai autokorelasi negatif)[1].

\subsection{Analisa Rescaled Range (Analisa R/S)}

Hurst, (1965), mengembangkan analisa $R / S$ (rescaled range analysis), metode statistik untuk menganalisa catatan panjang (long record) dari fenomena alam. Terdapat dua faktor yang digunakan dalam analisa ini, yaitu :

1. Range $(R)$ yaitu beda (selisih) antara maksimum dan minimum nilai akumulasi atau jumlah kumulatif dari $X(t, n)$ dari fenomena alam dari data waktu diskrit $t$ pada kutipan $n$ data.

2. Simpangan baku (standart deviation), $(S)$, diestimasi dari data amatan $X$.

Jika diberikan data runtun waktu $x_{t}$, maka

1.

$$
X(t, n)=\sum_{i=1}^{t}\left(x_{i}-\langle x\rangle\right)
$$

dengan $\langle n\rangle_{n}=\frac{1}{n} \sum_{i=1}^{n} x_{i}$

$X(t, n)$ adalah jumlah selisih data runtun waktu $y_{t}$ dengan rata-rata $n$ data pertama.

2. $R(n)$, self-adjusted range didefinisikan $R(n)=\max X(t, n)-\min X(t, n)$

3. Simpangan baku (standart deviation)

$$
S(n)=\left[\frac{1}{n} \sum_{i=1}^{t}\left(x_{i}-\langle x\rangle\right)^{2}\right]^{\frac{1}{2}}
$$

4. $R / S$, self-rescaled range $(R / S)=\frac{R(n)}{S(n)}$

$$
(R / S)_{n}=n^{H}
$$


Jika pada Persamaan 5 dikenakan operasi logaritma maka dapat dinyatakan sebagai berikut

$$
\log \left((R / S)_{n}\right)=H \log (n)
$$

Dari Persamaan 6 diperoleh parameter $H$ yaitu

$$
H=\frac{\log \left((R / S)_{n}\right.}{\log (n)}
$$

Dengan demikian untuk beberapa nilai $n$ diperoleh kemiringan garis regresi pada plot $\log (R / S(n))$ terhadap $\log (n)$ yang merupakan estimator dari konstanta $H$ sebagai long range proses dari proses Y.[1]

\section{Bahasan dan Hasil}

Dalam analisa data ekonomi keuangan, yang menjadi pusat perhatian adalah fluktuasi harga yang terjadi. Fluktuasi harga merupakan variabel yang menunjukkan naik turunnya harga. Pendekatan untuk fluktuasi harga adalah perubahan relatif atau return k-harian yang didefinisikan sebagai

$$
y_{t}=\ln p_{t}-\ln p_{t-k}
$$

dengan $k$ adalah selang waktu, dan $p_{t}, p_{t-k}$ adalah nilai tukar pada saat $t$ dan $t-k$. Gambar 1 menunjukkan grafik fluktuasi nilai tukar harian USD-IDR pada kurun waktu 1 Januari 1994 sampai dengan 20 Maret 2005.

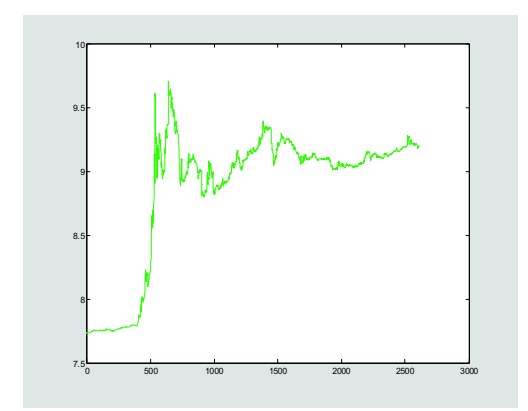

Gambar 1: Fluktuasi Nilai Tukar USD-IDR

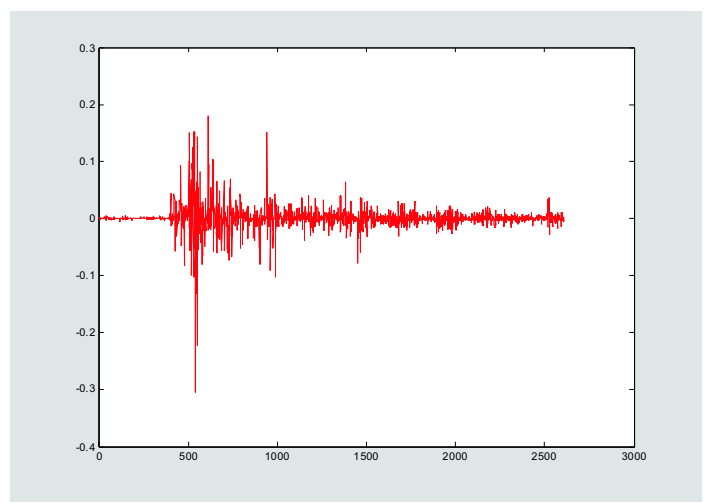

Gambar 2: Nilai Return Harian 


\subsection{Parameter Hurst dan Dimensi Fraktal Data Return 1- Harian}

Hal yang terpenting dalam menguji keberadaan sifat keserupaan diri pada data runtun waktu adalah ditemukannya parameter Hurst $(H)$ pada data return (Gambar 2) yang dianalisa sebagai parameter keserupaan diri. Salah satu metode untuk mendapatkan parameter Hurst adalah dengan menggunakan analisa $R / S$.

Pada analisa $R / S$ data dipecah sehingga masing-masing kelompok data sebanyak data, untuk $i=1,2, \cdots, 326$. Pada masing masing kelompok data dicari rata-rata kelompok, yaitu $\left\langle x_{n}\right\rangle=\frac{1}{n} \sum_{t=1}^{n} x_{t}$. Hal ini digunakan untuk menghindari asumsi bahwa keseluruhan data mempunyai rata-rata yang sama. Kemudian dengan Persamaan 5, tiap kelompok data dihitung jumlahan dari simpangan (selisih) tiap data dengan rata-ratanya. Dicari range $X(t, n)$ yaitu dengan mencari selisih maksimum dan minimum dari yang kemudian dibagi dengan simpangan baku dari keseluruhan data sehingga diperoleh nilai $R / S$. Keseluruhan prosedur diselesaikan dengan program Matlab. Parameter Hurst $(H)$ diestimasi sebagai kemiringan garis regresi dari plot $\log$ nilai $R / S$ dengan $\log n$.

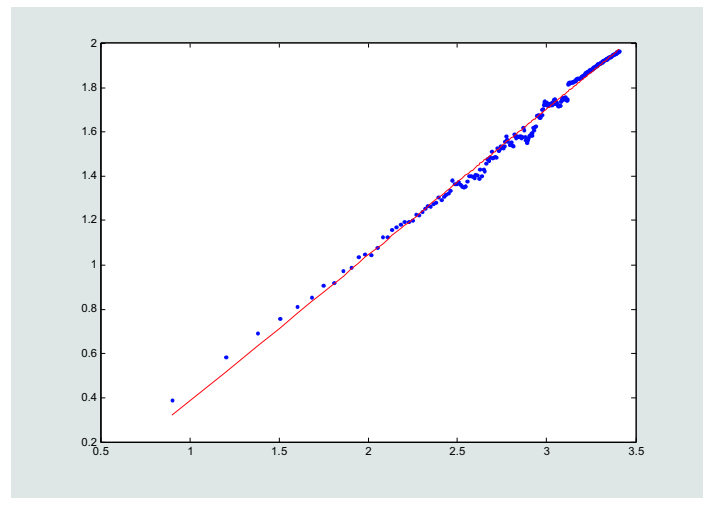

Gambar 3: Plot Log-log nilai R/S data return 1-harian

Hasil regresi terlihat pada Gambar3 dengan kemiringan sebesar 0.6596, sehingga parameter $H=0.6596$. Dari persamaan hubungan antara parameter Hurst dengan dimensi fraktal, dapat diketahui besar dimensi fraktal dari data return 1-harian yaitu . Nilai $D$ berada diantara $1<D<1.5$, berarti data return 1harian menunjukkan 'persistent behavior'. Hal ini menyatakan bahwa data return satu harian memiliki kecenderungan untuk bertahan pada suatu tren dalam jangka waktu yang lebih lama, artinya kenaikan tren pada saat ini memiliki peluang yang besar untuk diikuti kenaikan tren pada saat yang akan datang. Dengan prosedur 
yang sama seperti pada data return $k$-harian, dengan $k=5,10,15,20$, diperoleh nilai-nilai parameter seperti pada Tabel 1.

Tabel 1: Nilai parameter $\mathrm{H}$ dan dimensi $\mathrm{D}$

\begin{tabular}{|c|c|c|}
\hline Return k- harian & Parameter Hurst, H & Dimensi Fraktal, D \\
\hline Return 5-harian & 0,6532 & 1,3468 \\
\hline Return 10-harian & 0,7008 & 1,2992 \\
\hline Return 15-harian & 0.7008 & 1,2992 \\
\hline Return 20-harian & 0.7324 & 1,2676 \\
\hline
\end{tabular}

Nilai $D$ berada diantara $1<D<1.5$, berarti data return $k$-harian, $k=$ $5,10,15,20$ menunjukkan 'persistent behavior'. Hal ini menyatakan bahwa data return tersebut memiliki kecenderungan untuk bertahan pada suatu tren dalam jangka waktu yang lebih lama, artinya kenaikan tren pada saat ini memiliki peluang yang besar untuk diikuti kenaikan tren pada saat yang akan datang.

\subsection{Sifat Distribusi Scaling}

Pada bagian ini akan diuji apakah data return memenuhi sifat scaling. Pada Persamaan 2 disebutkan bahwa data runtun waktu memenuhi keserupaan diri bila

$$
X(t) i . d k^{H} X\left(\frac{t}{k}\right)
$$

dengan $H$ adalah parameter Hurst. $X(t)$ merupakan variabel acak dan dalam Persamaan 9 berarti bahwa kedua sisi dari persamaan tersebut mempunyai distribusi yang identik, sehingga persamaan diatas dapat dinyatakan bahwa

$$
P(X(t)) \approx P\left(k^{H} X\left(\frac{t}{k}\right)\right), \quad \text { untuk } k>0
$$

atau

$$
P(X(k t)) \approx P\left(k^{H} X(t), \quad \text { untuk } k>0\right.
$$

Jika $Y(t)=k^{H} X(t)$ didefinisikan sebagai variabel acak baru maka sesuai dengan Persamaan 4 dimana $a=k^{H}$ didapatkan

$$
P\left(k^{H} X(t)\right)=\frac{1}{k^{H}} f\left(\frac{1}{k^{H}} k^{H} X(t)\right)=\frac{1}{k^{H}} f(X(t))
$$

Dari pengamatan plot data return pada Gambar 2 dapat diasumsikan bahwa proses $X(t)$ stationer sehingga berdasarkan Persamaan 3 maka data runtun waktu $X(t)$ maka

$$
X(t)-X(0) i . d X(t+s)-X(t), \quad \text { untuk semua } s>0
$$

Dengan mengambil $X(0)=0$ maka fungsi dari Persamaan14 adalah,

$$
f(X(t))=f(X(t+s)-X(t)), \quad \text { untuk } s>0
$$


Dari Persamaan 13 dan 14 dapat dinyatakan sebagai berikut

$$
\frac{1}{k^{H}} f(X(t))=\frac{1}{k^{H}} f(X(t+s)-X(t))
$$

jika diambil $s=k$ untuk mengekspresi data return maka

$$
\frac{1}{k^{H}} f(X(t))=\frac{1}{k^{H}} f(X(t+k)-X(t))
$$

diambil $k=h, h^{\prime}$ maka

$$
\frac{1}{h^{H}} f(X(t+h)-X(t))=\frac{1}{h^{\prime H}} f\left(X\left(t+h^{\prime}\right)-X(t)\right)
$$

sesuai denagn Persamaan 4 maka Persamaan 18 dapat dinyatakan sebagai berikut:

$$
f\left(h^{H}(X(t+h)-X(t))\right)=f\left(h^{\prime H}\left(X\left(t+h^{\prime}\right)-X(t)\right)\right)
$$

Jika fungsi $f$ pada Persamaan 19 diinterpretasikan sebagai distribusi peluang maka

$$
\begin{aligned}
h^{H}(X(t+h)-X(t)) & \approx h^{\prime H}\left(X\left(t+h^{\prime}\right)-X(t)\right) \\
h^{H+1}\left(\frac{X(t+h)-X(t)}{h}\right) & \approx h^{\prime H+1}\left(\frac{X\left(t+h^{\prime}\right)-X(t)}{h}\right) \\
\frac{X(t+h)-X(t)}{h} & \approx\left(\frac{h^{\prime}}{h}\right)^{H+1}\left(\frac{X\left(t+h^{\prime}\right)-X(t)}{h}\right)
\end{aligned}
$$

Jika $\rho=\frac{X(t+h)-X(t)}{h}$ adalah sebagai variabel acak dan fungsi distribusi peluang/kepadatan $P_{k}(\rho)$, sehingga Persamaan 22 dapat dinyatakan sebagai

$$
P_{k}(\rho) k^{(H+1)}=Q\left(k^{-H-1} \rho\right)
$$

$Q$ adalah fungsi umum untuk menggambarkan distribusi peluang pada skala yang berbeda. Plot $P_{k}(\rho) k^{(H+1)}$ dengan $k^{-H-1} \rho$ pada data return akan membentuk disrribusi dasar untuk menentukan distribusi kesebangunan diri data return tersebut. Berikut adalah hasil plot pada data return nilai tukar mata uang USD-IDR dengan mengambil skala $k=10,15,20$.

Fungsi kepadatan peluang $P_{k}(\rho)$ dapat dihitung dengan membagi nilai frekwensi pada histogram dengan total jumlah data return.

Dari Gambar 3 menunjukkan bahwa variabel acak $k^{-1-H} \rho$ memenuhi sifat scaling pada skala dengan $k$ berbeda dan mempunyai kepadatan peluang $Q\left(k^{-1-H} \rho\right)$. Dengan hukum pangkat, fungsi $Q$ dapat didekati dengan

$$
Q\left(k^{-1-H} \rho\right) \approx C e^{-\left|k^{-1-H} \rho\right|}
$$

Persamaan 24 merupakan persamaan umum distribusi fraktal dari data nilai tukar mata uang Dollar Amerika terhadap Rupiah. Selanjutnya dengan metode fitting kurva diperoleh Gambar 4 yang menunjukkan bahwa data return berdistribusi NonGauss dengan data1 adalah $\rho(k=10)$, data2 adalah $\rho(k=15)$, data3 adalah $\rho(k=20)$ 


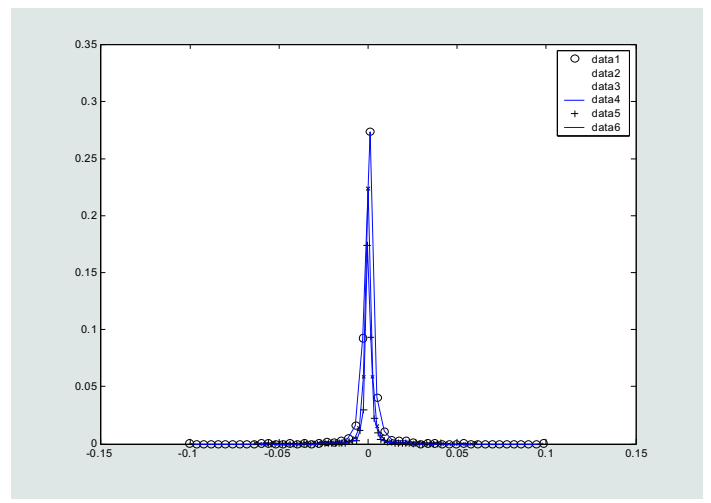

Gambar 4: Distribusi Data Return

\section{Kesimpulan}

Dari pembahasan pada bagian sebelumnya, dapat disimpulkan sebagai berikut:

1. Model dasar distribusi fraktal untuk data tukar mata uang Dollar Amerika terhadap Rupiah adalah sebagai berikut

$$
Q\left(k^{-1-H} \rho\right) \approx C e^{-\left|k^{-1-H} \rho\right|}
$$

yang berarti distribusi dari data tukar mata uang Dollar Amerika terhadap Rupiah menunjukkan distribusi NonGauss.

2. Data return nilai tukar mata uang Dollar Amerika terhadap Rupiah (USDIDR) mempunyai kecenderungan perilaku untuk bertahan pada suatu tren dalam jangka waktu yang lebih lama ('persistent behavior').

\section{Pustaka}

[1] Kaplan, I. (2003), Estimating the Hurst Exponent, Wavelat and Hurst,pp.1115.

[2] Taqqu, M.S, dan G. Samorodnitsky (1994), Stable Non-Gaussian Random Processes, Chapman and Hall, London.

[3] Papoulis, A. (1992), Probabilitas, Variabel Random, dan Proses Stokastik, Gadjahmada Universtas Press, Yogyakarta.

[4] Falconer, K. (1990), Fractal Geometry, John\&Sons, New York. 
[5] Bassingwaighte, J.B. (1994), Evaluating Rescaled Range analysis for time series, Ann Biomed Eng, New York.

[6] www.oanda.com, Foreign Exchange Services \& Trading. 